German Real Estate Return Distributions: Is There Anything Normal?

Richter, Johannes;Thomas, Matthias;Füss, Roland

Journal of Real Estate Portfolio Management; May-Aug 2011; 17, 2; ProQuest

pg. 161

\title{
German Real Estate Return Distributions: Is There Anything Normal?
}

\begin{abstract}
Executive Summary. This paper uses a sample of German commercial and residential property returns to estimate parameters for stable distribution functions. $A$ quantile-based estimation methodology is used to examine distributions of income, capital growth, and total returns. There are controls for the effects of property characteristics and for possible differences between appraisal-based and transaction-based return distribution parameters. The findings reveal that the assumption of normality in return distributions can be rejected for virtually all subsamples of all property types, and for all years from 2000 to 2009 . However, income return distributions are found to be less leptokurtic than those of capital growth. Building characteristics do not have a strong influence on distribution parameters, while transaction-based returns do differ from appraisal-based returns for retail and residential properties.
\end{abstract}

*EBS Business School, D-65189 Wiesbaden, Germany or johannes.richter@ebs.edu.

**EBS Business School, D-65189 Wiesbaden, Germany or matthias.thomas@ebs.edu.

***EBS Business School, D-65189 Wiesbaden, Germany or roland.fuess@ebs.edu. by Johannes Richter*

Matthias Thomas**

Roland Füss***

One of the primary tenets of property investment research is that return distributions of direct real estate show "fat tails," and therefore deviate from normality. This has important implications for the portfolio management decisions of institutional investors. When pricing and allocation models are based on normality assumptions, investment risk can be severely underestimated for investments exhibiting non-normal return distributions, especially negative skewness and positive excess kurtosis. Knowledge of non-normal return distribution parameters allows for a more precise estimate of the severity of fat tails, which is vital for a sound risk assessment. Thus, whether certain types of assets deviate more or less from normality in their return distributions is highly relevant for the adjustments of stochastic risk assessment models.

Prior research has provided insight into the shape of return distributions for different property types and their characteristics in various countries. A number of studies show that real estate returns and risk are quite distinct from the risk/return characteristics of other asset classes. ${ }^{1}$ In addition to the research on the unique nature of real estate returns, there is also a body of literature comparing return characteristics among real estate sectors.

For instance, Myer and Webb (1993) investigate NCREIF returns from 1978 to 1990 for different property types (office, retail, $R \& D$, warehouse) with respect to their distribution characteristics. According to the Jarque-Bera test, the 
Kolmogorov-Smirnov (KS) test, and the chi-square goodness-of-fit test, the assumption of normally distributed returns can be rejected for all property types.

In the context of deriving efficient portfolios by using mean-variance (MPT) and mean absolute deviation (MAD) optimization techniques, Byrne and Lee (1997) confirm the non-normality of NCREIF returns for most property types for the 1983-1994 sample period (according to the Jarque-Bera test).

Coleman and Mansour (2005) developed a quantitative asset allocation model to address the empirical stylized fact of leptokurtic and skewed property return distributions. By assuming that property returns follow a non-central Student- $t$ distribution, they first employ Bayesian econometrics to estimate the full predictive conditional density of future returns. The conditional moments are then used as input variables in a meanshortfall variance optimizer. The dataset comprises quarterly returns of the four NCREIF sector indices-apartment, industrial, office, and retailover the period from 1978 to 2003. The authors demonstrate that the shortfall risk optimization shifts the efficient frontier substantially to the left of the mean-variance efficient Markowitz frontier within the return-risk space.

Young and Graff (1995) were among the first to apply McCulloch's (1986) quantile-based estimation technique for stable distribution parameters to real estate returns. Their sample covers 1980 1992 , and consists of 13,958 annual total property returns from the NCREIF index for the office, retail, warehouse, and research and development property sectors. For each year, the parameters of the stable return function suggest an infinite variance distribution (i.e., a rejection of the assumption of normality). Their analysis supports the conclusion that there is one constant characteristic distribution exponent for the years analyzed. ${ }^{2}$

However, the skewness shifts from left to right over time (i.e., the $\beta$ coefficients decreased for all property types). In general, Young and Graff (1995) found that property-specific investment risk was heteroscedastic. They concluded that the characteristic exponent deviates strongly from that of the normal distribution, thus implying fat tails. These have a significant impact on portfolio management, because, compared to normally distributed returns, far more properties are needed to reduce asset-specific investment risk.

Young, Lee, and Devaney (2006) extended the same methodology to the United Kingdom for the 1981-2003 period. Their data consisted of 269,853 total return observations from IPD. Similar to Young and Graff's (1995) results, they find that the characteristic exponent of distributions is comparatively constant over time. Moreover, real estate return distributions are found to be heteroscedastic with respect to skewness and the magnitude of real estate asset-specific risk. In their conclusion, they question whether mean-variance or mean absolute deviation analyses are more appropriate for the risk assessment of direct real estate investments.

Two additional studies that also use McCulloch's (1986) methodology essentially confirm the findings of the above-mentioned studies regarding characteristic exponents, skewness, and real estate asset-specific risk behavior over time. Graff, Harrington, and Young (1997) use return distributions of 4,593 properties from 1984 to 1996 from the Property Council of Australia index. They find no significant differences between their sample and the distribution shape of properties in the United States.

Young (2008) updates the prior empirical analyses for the U.S. using NCREIF data on 33,745 properties from 1980 to 2003 . His findings confirm those of the earlier studies with respect to heteroscedasticity in asset-specific risk, and nearly constant characteristic exponents of return distribution over time and property type.

Using a capital-weighted fund index, Maurer, Reiner, and Sebastian (2004) investigate return characteristics of German open-ended fund returns from 1975 to 2003 . They find that monthly fund returns display similar characteristics to direct property returns. Besides autocorrelation, they generally exhibit low means and volatilities. Although open-ended fund returns are naturally 


\begin{tabular}{|c|c|c|c|c|}
\hline \multicolumn{5}{|c|}{$\begin{array}{c}\text { Exhibit } 1 \\
\text { Descriptive Statistics }\end{array}$} \\
\hline Year/Period & $\begin{array}{l}\text { No. of } \\
\text { Properties }\end{array}$ & $\begin{array}{l}\text { No. of } \\
\text { Observations }\end{array}$ & $\begin{array}{l}\text { Avg. Rentable } \\
\text { Area (per sqm) }\end{array}$ & $\begin{array}{l}\text { Avg. Economic } \\
\text { Age in } 2009\end{array}$ \\
\hline Retail & 1,604 & 5,556 & 6,999 & 25.4 \\
\hline Office & 2,409 & 10,753 & 9,675 & 21.1 \\
\hline Residential & 4,970 & 12,782 & 1,718 & 35.3 \\
\hline
\end{tabular}

Notes: The data come from IPD. Rentable area denotes the average number of square meters per property in 2009. Economic age stands for the average difference between the current year and the year of the last major renovation or development for all observations.

linked to property returns, they are influenced by debt, liquidity, and foreign investments, and may thus exhibit different characteristics than direct real estate investments.

This paper aims to contribute to the abovementioned literature in four distinct ways:

1. The study examines the possible differences among income return, capital growth, and total return. This differentiation is not merely theoretical, however, as these sources of return may be of varying levels of importance to investors. For example, income return may be more important to income-oriented investors with longterm investment horizons; capital growth, on the other hand, may be more relevant for opportunistic investors with shorter investment horizons. Moreover, investors need to reinvest cash flows, while capital growth remains a book value until the property is sold. Thus, investors can benefit from knowledge about different investment risks that are reflected in return distribution parameters.

2. The study investigates whether there are substantial disparities among return distribution parameters in five major German cities, as well as a group of other locations. Further analysis may determine whether investors would benefit from incorporating regionally idiosyncratic shapes of return residual distributions, as well as geographic diversification, into a quantitative investment analysis.

3. The study also examines investment risk among properties with certain characteristics. While previous studies have shed light on return distributions and focused on property type return distributions, most have neglected to study the influence of property-specific characteristics on return distributions. Hence, properties with certain characteristics may exhibit differing return distributions that, in turn, can affect asset selection decisions and portfolio construction. For example, return distributions of certain types of properties with various degrees of "normality" will impact portfolio management decisions.

4. Robustness checks are used to test whether the results remain stable when distribution parameters are derived from transaction-based rather than appraisal-based returns. This analysis can thus manage the possibility that smoothing may influence appraisals, therefore affecting the results of the analyses.

The Data and Methodology section provides an overview of the dataset, the theoretical background, and the methodology used. The estimates of distribution parameters are discussed in the Empirical Result section and are tested for robustness in the Robustness Checks section. The final section presents concluding remarks.

\section{Data and Methodology}

The sample consists of 8,983 properties with a total of 33,228 annual return observations derived from the German IPD Index DIX. The type of use is broken down among retail (1,604 properties), office $(2,409)$, and residential $(4,970)$, and the properties are geographically distributed across Germany. The sample time period is 2000-2009. Exhibit 1 gives the descriptive statistics. 
The methodology presented by McCulloch (1986) and used in Young and Graff (1995) is applied to make the findings comparable to those of other studies. The technique generates consistent parameter estimates from a stable distribution by interpolating a general characteristic function (McCulloch, 1986):

$$
\psi(t)=\left\{\begin{array}{c}
i \delta t-|\gamma t|^{\alpha}\left(1-i \beta \operatorname{sgn}(t) \tan \frac{\pi \alpha}{2}\right) \\
\text { with } \alpha \neq 1 \\
i \delta t-|\gamma t|^{\alpha}\left(1+i \beta \frac{2}{\pi} \operatorname{sgn}(t) \log |t|\right) \\
\text { with } \alpha=1
\end{array} .\right.
$$

Following Equation (1), stable distributions using four parameters alpha, beta, gamma, and delta, as described in the literature above, can be characterized.

1. Alpha represents the characteristic exponent of the distribution function. It lies in the half-open range of $(0,2]$, and determines the rate at which the tails of the distribution decline to zero. A higher value means that the distribution tapers off more rapidly at the upper and lower ends. For the normal distribution, with $\alpha=2$ and for functions with a value $<2$, the distribution's variance is infinite. A value $\leq 1$ implies that no mean exists (McCulloch, 1986). In the context of this paper, alpha can be interpreted as a measure of investment risk, because it describes the distribution behavior at the tails.

2. Beta measures the distribution's skewness or asymmetry. In other words, $\beta$ indicates whether the left (negative skew, negative beta) or right (positive skew, positive beta) tail is longer. The range of possible values is $[-1,+1]$. When $\alpha$ approaches 2 , the distribution converges to normality and $\beta$ loses its relevance (McCulloch, 1986).

3. Gamma is a scale parameter indicating the narrowness or broadness of the shape of the distribution curve. Its value is finite for all stable distributions. However, the standard deviation is finite only for the normal distribution ( $\alpha=2$ and $\gamma=\sigma \sqrt{2}$ ). The scale parameter can be thought of as a generalization of the standard deviation (Young and Graff, 1995). In this context, $\gamma$ represents a property-specific risk (McCulloch, 1986).

4. Delta represents the location parameter in which the distribution is centered. Its value can be reasonably interpreted as long as alpha is significantly larger than 1 in a statistical sense (McCulloch, 1986).

The same model used by Young and Graff (1995) among others is applied to estimate the distribution of annual $\log$ return residuals:

$$
r_{t}(p)=\mu_{t}[h(p)]+\varepsilon_{t}(p),
$$

where $h(\cdot)$ is a dummy variable indicating property type (retail, office, or residential). The total expected return, $\mu_{t}$, in any year $t$ is a function of $h(\cdot)$ and a stable error random variable $\varepsilon_{t}$, which is i.i.d. with a variance that is not necessarily finite. As a consequence, the model in equation (2) does not assume normally distributed asset-specific risk, but implies that two properties of the same type have identical expected returns and residual distributions. The asset-specific error term (e.g., investment risk) does not necessarily have a finite variance.

As Young and Graff (1995) note, parameter estimates are asymptotically normal. Thus, a null hypothesis of equal parameters can be tested for either different years or different property types with the following expression:

$$
\sum_{i=1}^{n} w_{i}\left(x_{i}-\bar{x}\right)^{2}
$$

which is $\chi^{2}$ distributed over $n-1$ degrees of freedom, where $n$ is the number of parameters, $w_{i}$ is the observation weight, defined as the reciprocal of the estimate's variance, and $\bar{x}$ is the weighted average of $x_{i}$ with weight $w_{i}$. Risk management will be facilitated if parameters are found to be stable over time, because fewer variables will be needed to quantify the investment risk.

In order to test for the possible influence of property characteristics on return distributions, the observations are divided into two groups according to the following characteristics: economic age, 
rentable area, quality of buildings, and property location.

The economic age of a property is defined as the difference between the year of return observation and the year of construction or, if applicable, the year of the last major renovation. It seems obvious that return distributions of newer properties expose fatter tails or at least broader shapes than those of older properties. For example, according to the German valuation ordinance, a change in market rent of $1 €$ per square meter has a stronger effect on the capital growth of newer properties than on older ones, assuming an identical total period of economic remaining life for the buildings. ${ }^{3}$ Changes in market rent income will impact returns on newer properties more strongly, as their estimated income is capitalized for a longer period into the future. This will result in a lower alpha or a higher gamma.

Rentable area is defined as the number of square meters reported in 2009. Properties of different sizes and locations may tend to attract different types of investors, which may also result in altered return characteristics. The average value of sustainable income per square meter of rentable area serves as a proxy for building and location quality.

By nature, properties of the same type but varying measures of quality might certainly trigger various levels of investment risk. The property building and location quality would then be reflected in alpha and gamma. Several robustness checks are applied to control for the strength of impact of the different levels of these variables on investment risk in the two groups of properties.

In order to check whether there are distinct parameters for local submarkets, the sample is divided into six subsamples, representing properties in Berlin, Dusseldorf, Frankfurt, Hamburg, and Munich, as well as a group containing all the other properties. ${ }^{4}$

Finally, the return distributions from the original sample of appraisal-based returns can be compared to those of the transaction-based returns.
Assuming perfectly accurate property appraisals, the return residual distribution characteristics are not expected to differ significantly. As appraisalbased returns are generally assumed to be smoothed, it can be hypothesized that transactionbased returns are less leptokurtic, and/or display larger gammas as properties "catch up" to the real (but a priori unknown) market value (as opposed to the appraised value). However, note that lower values for alphas and larger values for gammas do not necessarily imply smoothed returns, because investors might be more inclined to sell a property in a year when a massive change in market value is expected.

\section{Empirical Results}

Exhibits 2-4 give the estimates for the distribution parameters alpha, beta, gamma, and delta. Because observations are adjusted for group means, delta represents the center of the distribution and does not provide further information. It is only reported here for the sake of completeness.

The $\chi^{2}$ test statistics indicate the probability that the parameters will be constant over time. The critical values for nine degrees of freedom are 16.92 and 21.67, respectively, for the $95 \%$ and $99 \%$ confidence levels. Exhibits $2-4$ show the parameter estimates for the appraisal-based retail, office, and residential property returns.

For income returns, the characteristic distribution exponent alpha lies within the range of 1.34-1.62. These alpha values are in line with the findings for total returns by others (e.g., Young, Lee, and Devaney, 2006; Young, 2008). All alphas are significantly lower than 2 , the characteristic value for the normal distribution, so normality can be rejected with a very high probability for all years.

Regarding the retail sector, the variation in alpha over time seems to be moderate, and the test statistic for the $\chi^{2}$ distribution does not reject the null hypothesis of a constant alpha. For office and residential, the test statistics are indeed significant at the $95 \%$ confidence level. 


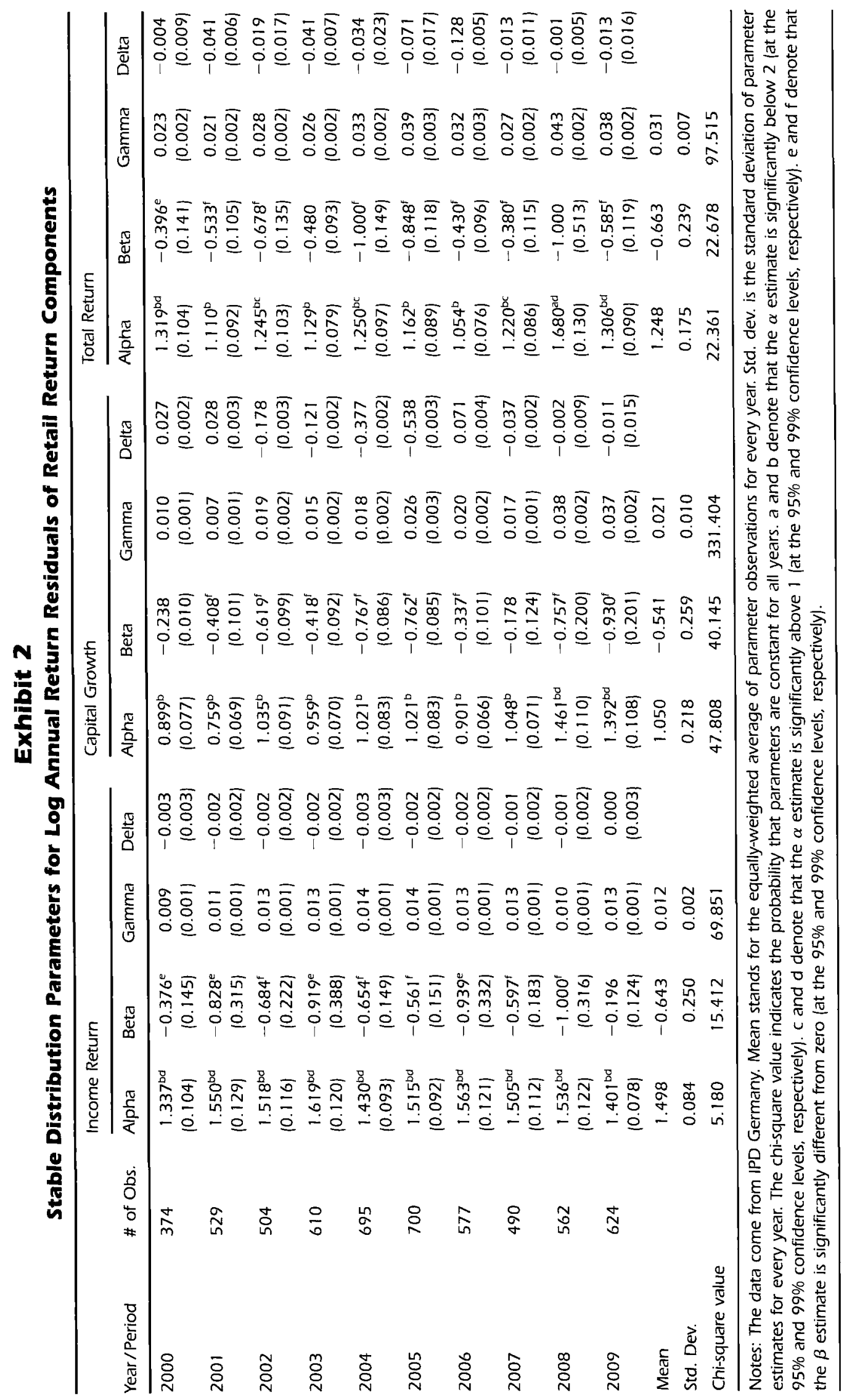




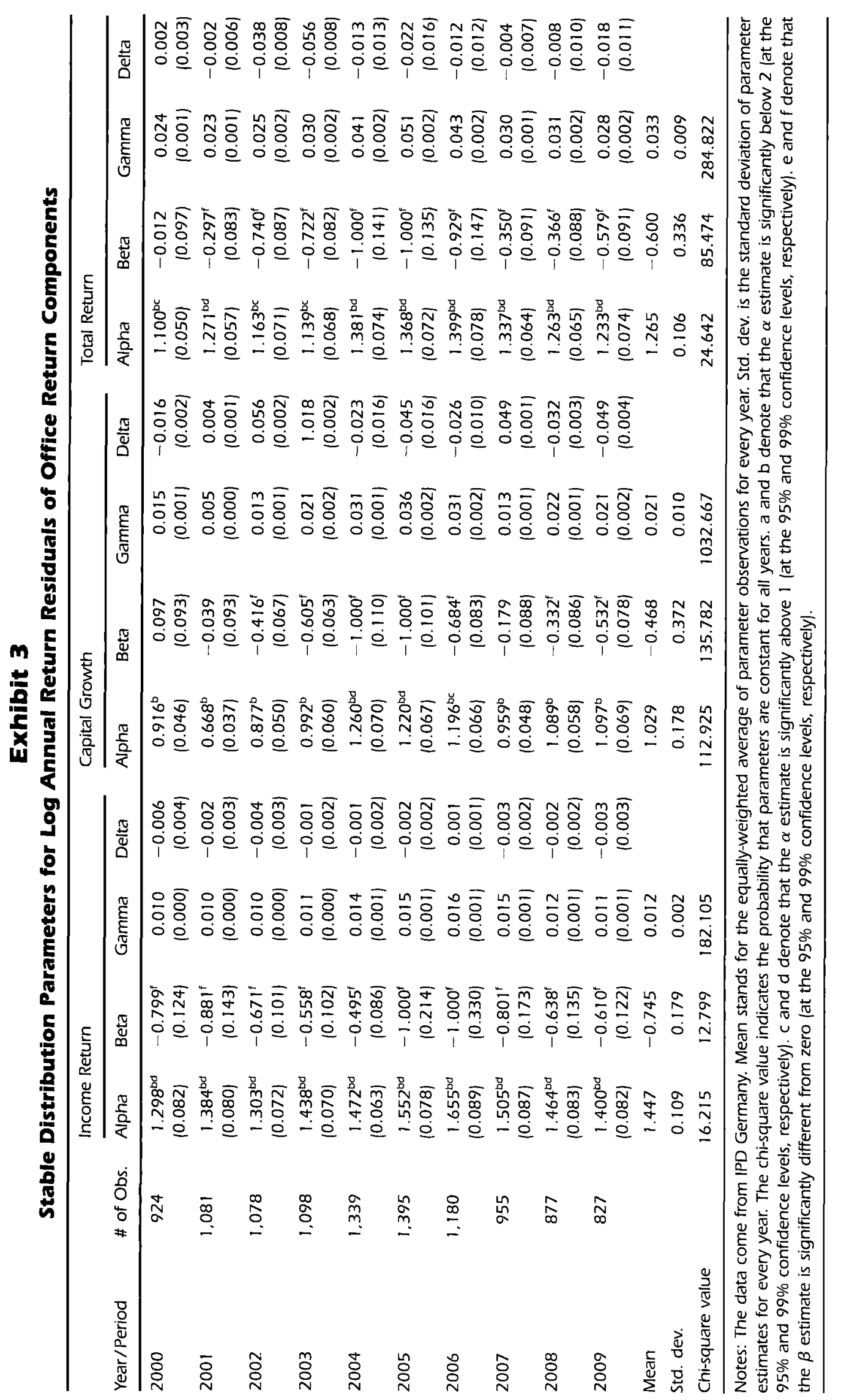




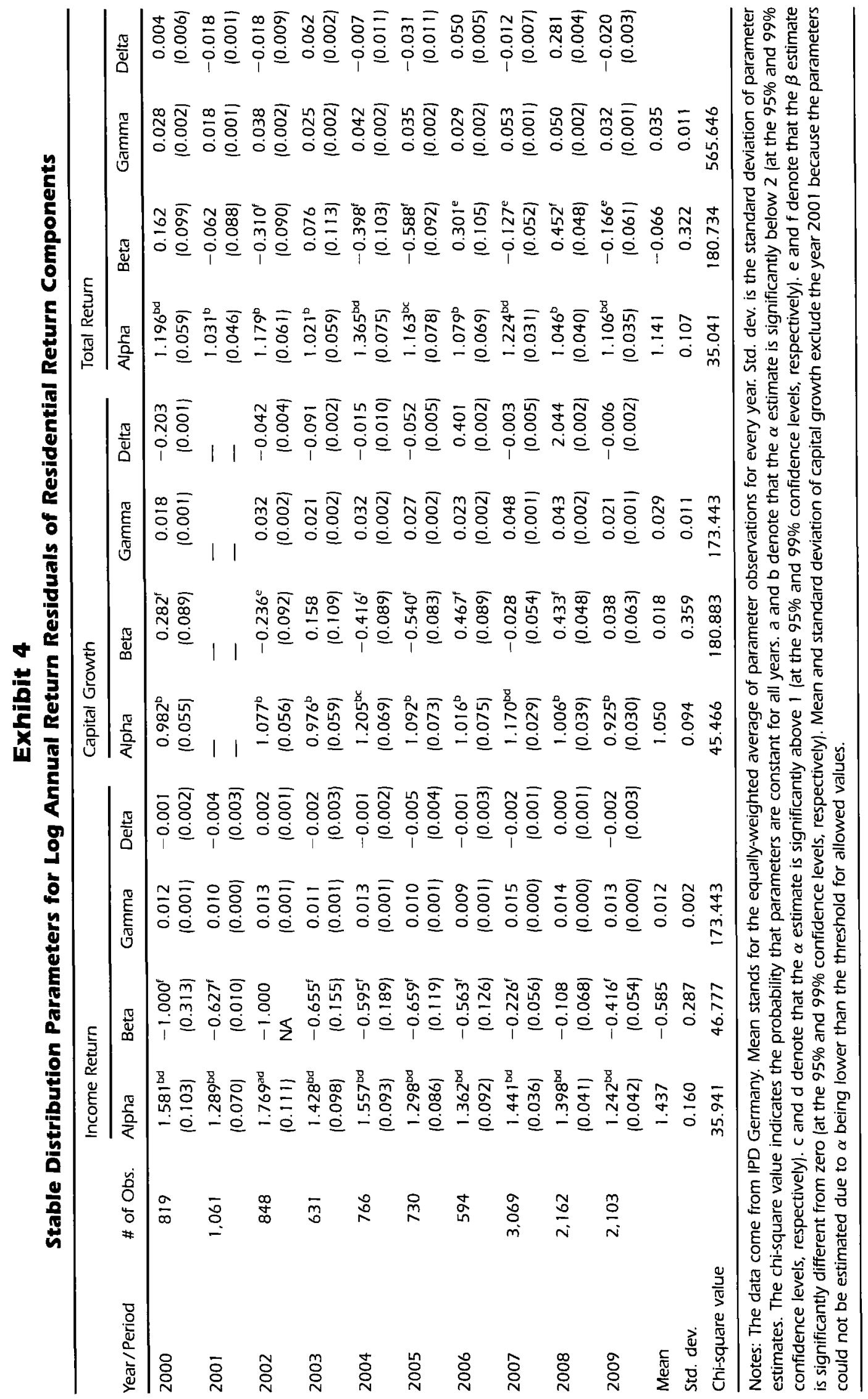


In contrast to other studies, however, no trend is found in betas. For almost all distributions, beta remains significantly below zero, signaling a skew to the left. Because the empirical $\chi^{2}$ value for gamma is larger than the critical value, the investment risk for income return is heteroscedastic.

The results for capital growth are striking, because the presented alpha values are considerably below those for income return. Moreover, the alpha for capital growth appears to be highly erratic over the years, and the value is significantly above 1 in only six out of thirty cases. If alpha is not larger than 1 , then the distributions do not have a mean, because the distribution tails taper off fairly slowly. Betas for capital growth are all negative, which is similar to those found for income return.

Not surprisingly, the alphas for total return vary between those for income return and capital growth. Note that the characteristic exponents for total return distributions are on average somewhat lower than those found in the literature for other countries $(1.25,1.27,1.14$, respectively, for retail, office, and residential).

The $\chi^{2}$ test for parameter stability also rejects the null of constant alphas or gammas over time. Thus, asset-specific risk for retail properties is time-varying and significantly larger than implied by a normal distribution. These results are particularly important for buy-and-hold investors, who might be more focused on income return, and for opportunistic investors, who seek quick capital gains.

Furthermore, no substantial differences are found for retail, office, and residential properties (except that the alphas of residential are somewhat lower than those of retail and office). The investment risk that comes with capital growth is significantly higher than that arising from income and total return. A graph of total return residual distribution shapes is given in Figure A.1 in the Appendix.

Thus, the heteroscedasticity of alpha in German property return residuals combined with the fluctuations of betas and gammas results in distributions of property-specific investment risk that require considerably more complex risk management. Risk management models need to account not only for time-varying risk in gamma, but also for changes in the characteristic distribution parameter alpha, and possibly for beta as well.

Interestingly, the estimated total return parameters differ slightly from those found for Australia, the U.K., and the U.S. The characteristic exponents of return residual distributions are not as stable over time, and are on average slightly lower than in the other countries (e.g., the distributions are more leptokurtic). To be more precise, income return residual alphas are roughly within the range of total return alphas for other countries, but capital growth alphas are considerably lower.

The discrepancies for income return alphas on the one hand and capital growth and total return alphas on the other imply that investors need to adjust their portfolio strategies as investment periods vary. An investor who is purchasing properties to hold until the end of their economic lives (and thus neglecting capital growth of the buildings) can expect considerably higher alphas than an investor who is actively rebalancing his portfolio. Moreover, quantitative risk modeling is complicated further by the fact that a mean value for the residual distribution does not exist for some periods, especially for capital growth.

\section{Robustness Checks}

The observations are split into subsamples according to various property characteristics to test the robustness of the results. The return residual distribution parameters are then compared for the two groups separately. This allows for further insights into the relationship between property and return characteristics, which in turn can lead to more comprehensive and accurate investment risk modeling and institutional portfolio allocation.

The alpha values of the large and small building subsamples are compared for all the property types. Exhibit 5 shows that the absolute differences are moderate. But the difference is still significant for residential and office properties. 


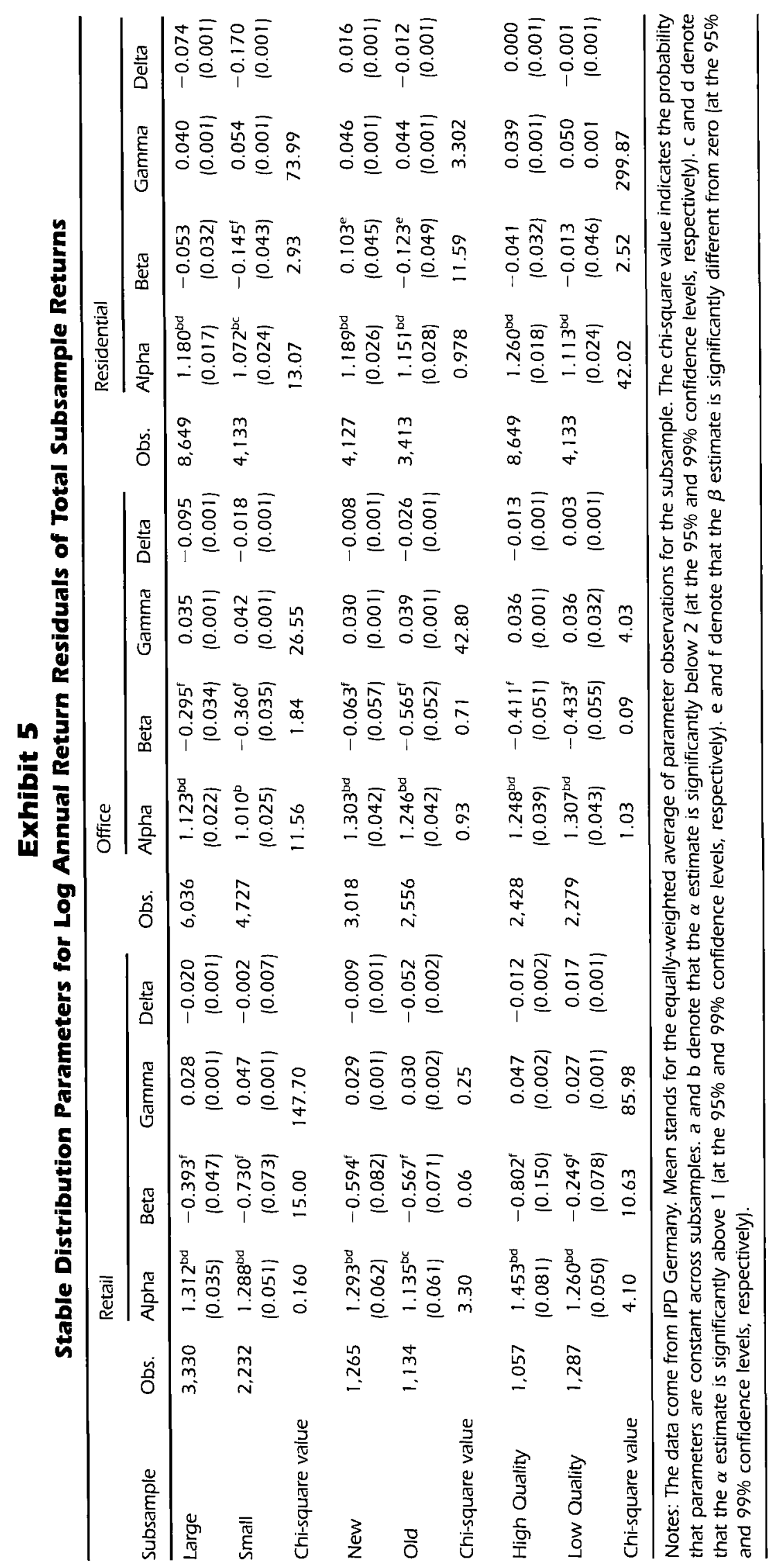


Overall, the parameters are not fundamentally different when compared to those of the entire sample.

There are mostly insignificant differences between new and old properties, which means investors are not likely to find different parameters when specializing in one of these two groups. Note that the significant difference in beta between old and new residential properties is the sole exception (beta is more positive for the newer properties). This means that the probability of large positive deviations is higher for new properties.

The same is true for the two groups of high- and low-quality properties, except for the alphas in the residential sector and betas in the retail sector. Interestingly, the betas for all the subsamples are negative, a characteristic usually not preferred by investors over positive skewness.

In summary, the results in Exhibit 5 do not show that the building characteristics size, economic age, or property quality significantly influence the return distribution alphas or betas (besides the above mentioned exceptions).

The return residual distributions for regional submarkets are shown in Exhibits 6-8. Within the retail sector, alphas are very homogeneous for all groups. The $\chi^{2}$ value indicates significant differences for betas with respect to capital growth. Most coefficients are negative, so distributions are negatively skewed.

The results for the office sector, however, are not as robust. None of the alphas or betas are equal within the analyzed local markets (except the beta of income return). The mean values for alpha and beta are close to those of the other sectors, with betas for all regional markets significantly below zero.

Note further that, within the residential property sector, the regional differences are even more striking. All the $\chi^{2}$ values for income return, capital growth, and total return are highly significant for alphas and betas. Investors can thus expect assetspecific risk distributions for local submarkets of residential and office properties. For purposes of portfolio construction, this underscores the importance of conducting full due diligence on local submarkets, in addition to the usual geographic diversification.

If the property appraisal process is assumed to affect the distribution characteristics for any reason, then the alpha parameter derived from transaction-based data is likely to show distinct behavior. ${ }^{5}$ Possible differences in return residual distribution parameters can be examined by comparing the transaction-based returns with the sample of appraisal-based returns from the last section (Exhibit 9). ${ }^{6}$

For the entire 2000-2009 period, the parameter estimates are similar to the average estimates for single years shown in the previous tables. On the one hand, total return alphas are substantially higher for the transaction-based return residuals in the retail and residential sectors (e.g., the distribution is much steeper for appraisal-based data). This is obvious if it is assumed that appraisals do not entirely incorporate changes in the market value of properties, which results in the highly peaked distribution. ${ }^{7}$ Furthermore, the gammas of the transaction-based return residual distributions are significantly higher. However, this is not irrefutable evidence that this is a direct consequence of smoothed appraisals. As it does not allow for conclusions about cause and effect, properties are more likely to be transacted in years when they are undergoing a steep change in market value (upward or downward).

Moreover, the lack of significance for differences in alphas for the office sector negates the evidence regarding this effect. Another potential cause of the severe leptokurtosis might be that the German property market is less transparent than markets in other countries (Schulte, Rottke, and Pitschke, 2005). If there is less information available in the valuation process, it might be more difficult to incorporate comparatively small changes in the (true) market value into appraisals. ${ }^{8}$

Interestingly, the betas estimated for the transaction-based sample in all cases are signifi- 


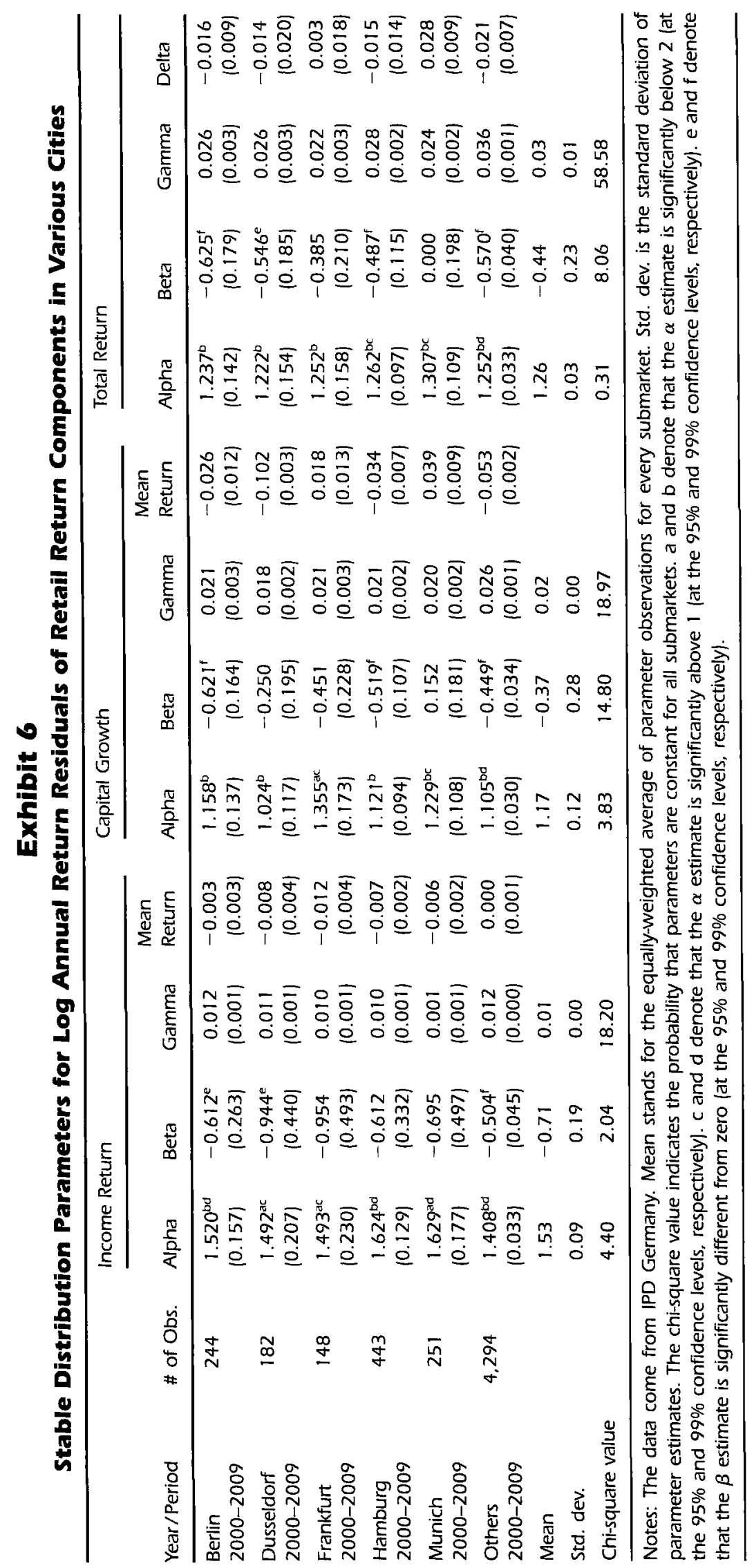




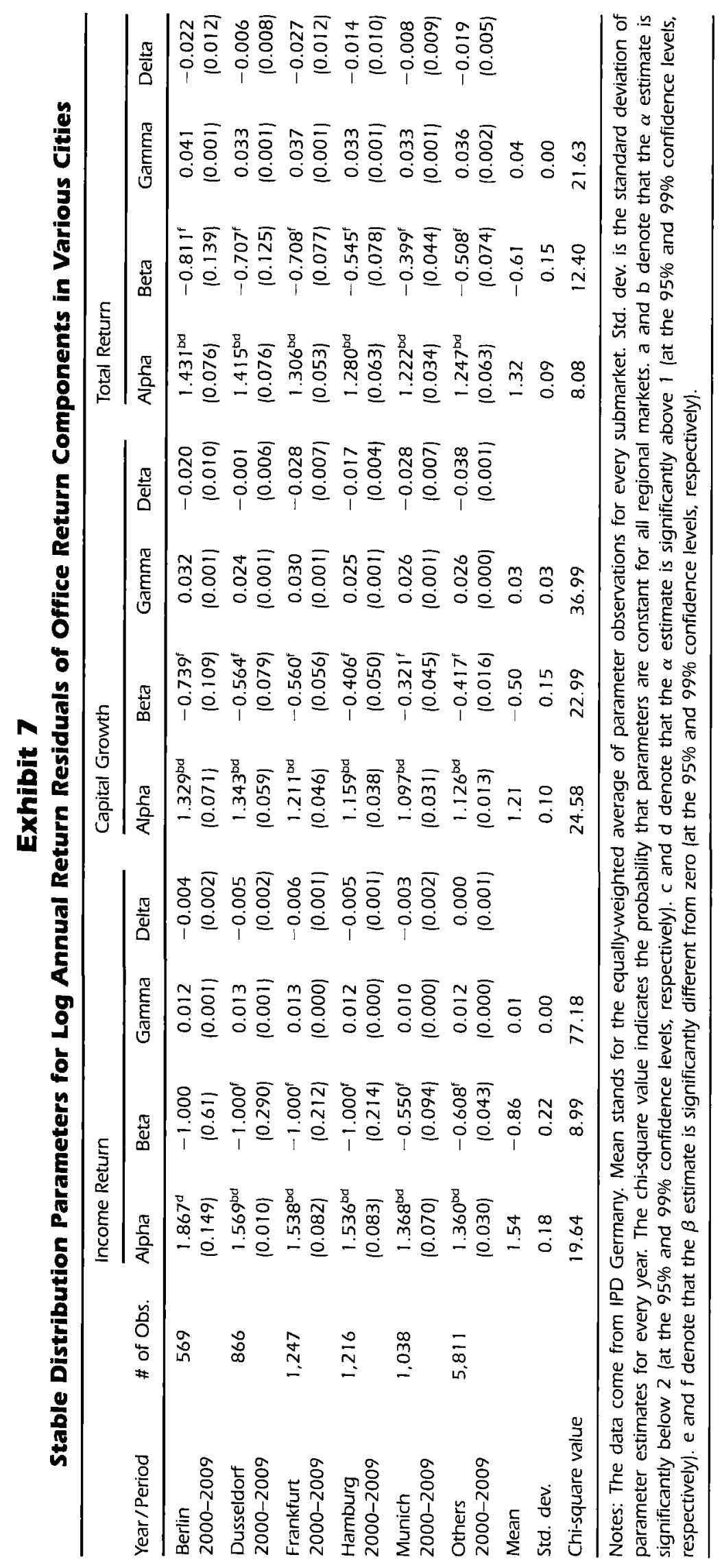




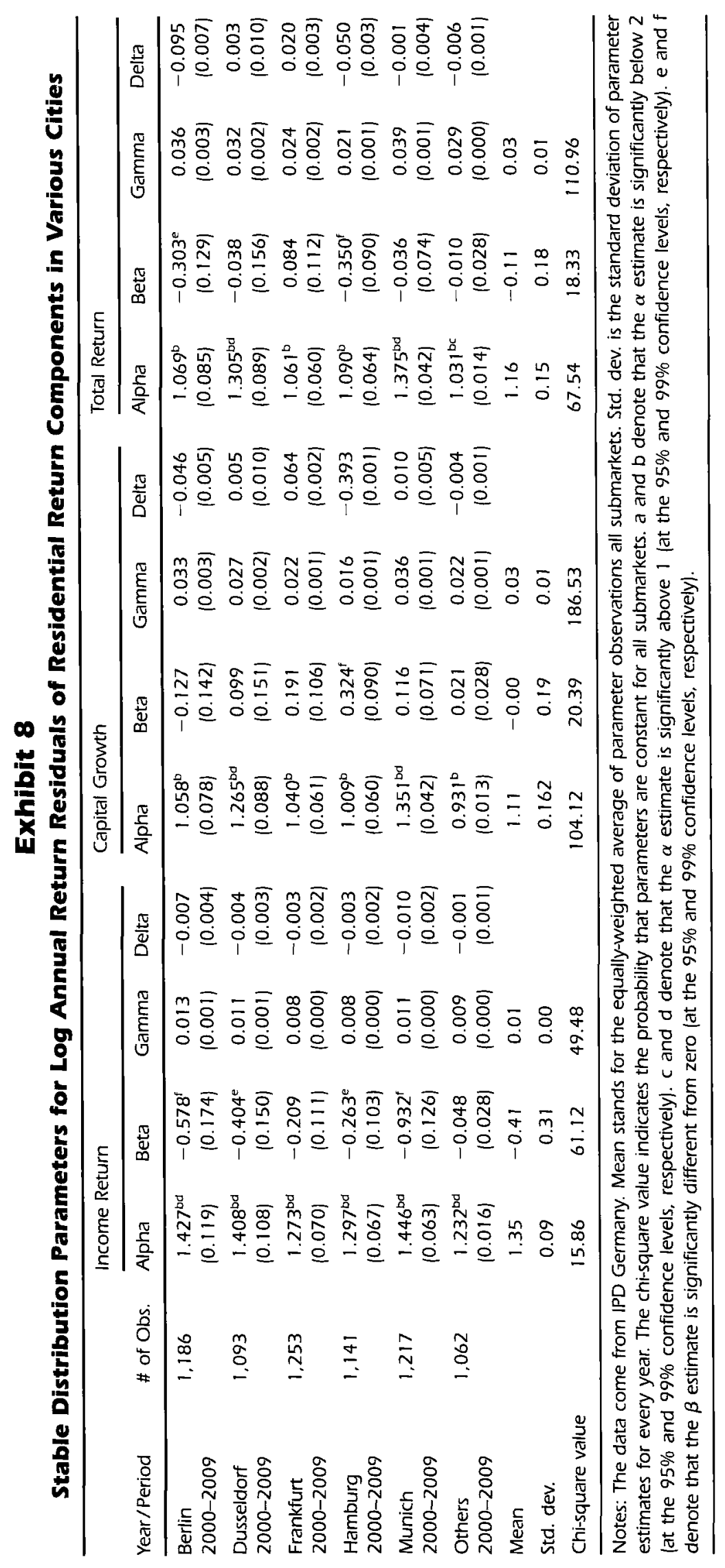




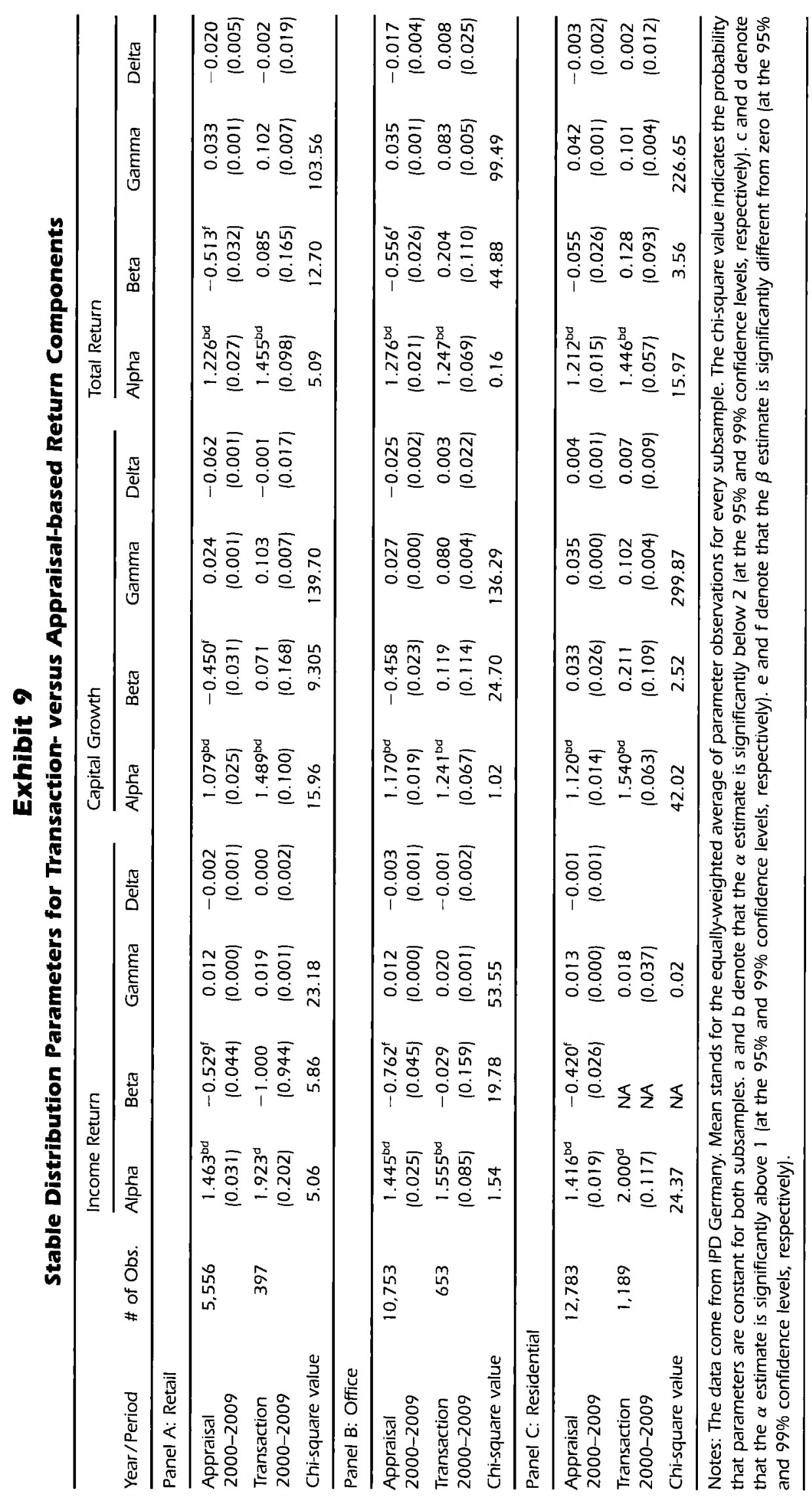




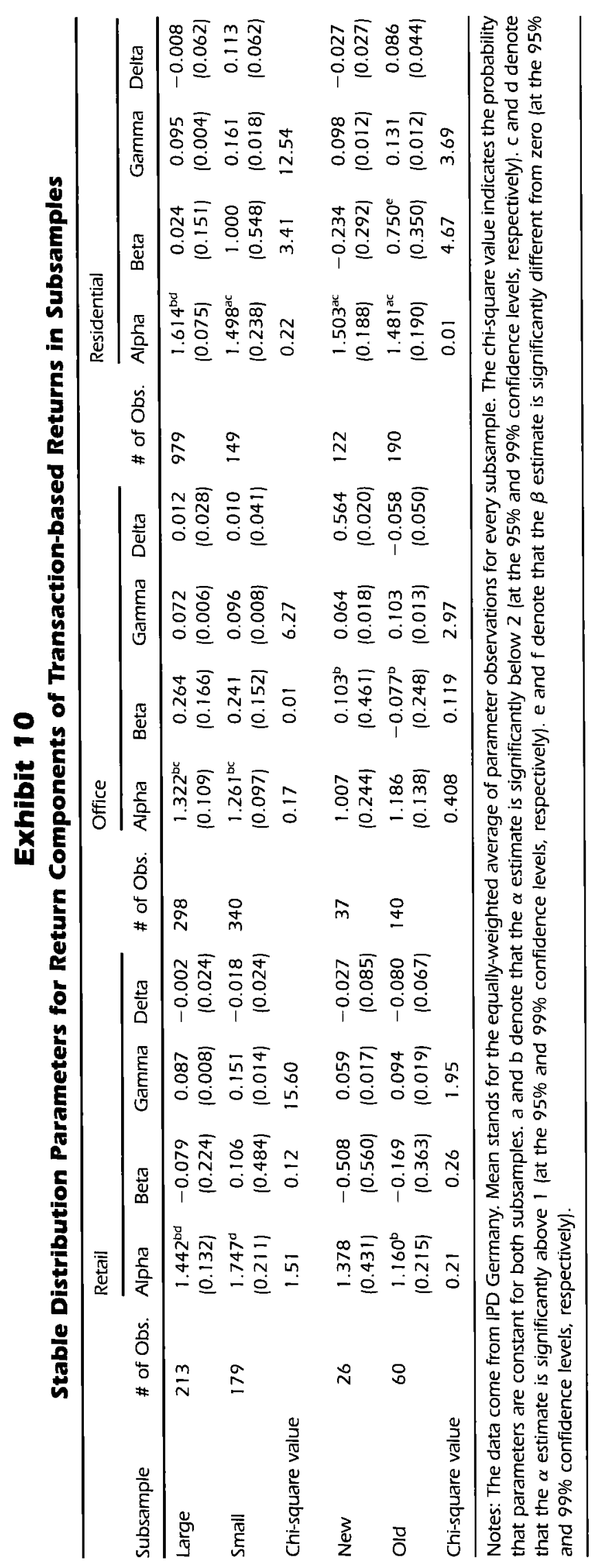


cantly higher than those for the appraisal-based sample (with two exceptions for income return, where betas lose their significance as alphas approach the value of 2). This indicates that the distribution is more positively skewed for transactionbased returns. Outliers are thus more likely to occur on the right side of the distribution.

Because transaction-based return residual distribution parameters have been found to differ from those of appraisal-based returns, the transactionbased returns are further divided into subsamples according to property size and economic age. ${ }^{9}$ This allows for a more detailed analysis of whether there are differences in distribution shapes among these groups. If one of these groups is believed to have more precise property appraisals than the others, then the distribution parameters should be closer to those of the appraisal-based subsample, because there would be less smoothing needing to be "corrected" by transactions.

However, the results in Exhibit 10 do not show significant differences for alphas, and they show only one out of six differences for betas. Thus, no evidence is found that return residual distributions for transaction returns vary with the property characteristics tested.

Ultimately, property characteristics may influence return residual distribution parameters in some cases. Regional submarkets seem especially likely to differ, at least for the residential and office sectors. For retail and residential properties, appraisal-based returns are different from returns generated by transactions, which might be the result of smoothed property appraisals.

\section{Conclusion}

McCulloch's (1986) quantile-based methodology is used to estimate stable distribution parameters for German commercial and residential property return residuals. The study extends the work of Young and Graff (1995) to the relatively large but still not fully transparent German investment market. Supplemental information is also provided about separate distribution residuals for income return, capital growth, and total return, as well as for the influence of property characteristics.

One of the major findings is that return residual distribution parameters are substantially different for income return, capital growth, and total return. Income return residual distributions exhibit fewer fat tails than those of capital growth. The shape of total return residual distributions is somewhere between their income return and capital growth counterparts. The low characteristic exponents of capital growth returns actually imply that return distributions must be assumed to lack a mean. This might further complicate quantitative risk management and portfolio planning.

An explanation might be that income returns are rather continuous cash flows and in general do not change abruptly. In contrast, capital growth can be affected from economic shocks, which can be substantial in both directions. This is because capital growth might be subject to appraisal smoothing and thus a shock in the valuation can be more pronounced than a change in income returns.

Generally, the results presented here indicate that investors can benefit from the knowledge about varying distribution shapes for return residuals. Investors pursuing buy-and-hold strategies might need to incorporate different asset-specific risk parameters compared to opportunistic investors who seek only shorter holding periods. This is because income return is more important for the former, while capital growth and total return are likely to be more important for the latter.

Note also that characteristic exponents and standard measures of risk gamma behave erratically over time. Thus, asset-specific investment risk must be considered heteroscedastic or timevarying; the characteristic exponents are comparatively stable only for income return.

Robustness checks compare large versus small, old versus new, and high- versus low-quality properties, but in general there are no significant differences. No property characteristic was identified for which the distributions' deviations from normality either increase or decrease significantly for all property sectors simultaneously. 
Regarding the retail and residential sectors, appraisal-based return residual distributions differed significantly from those of transaction-based returns. It is possible that property appraisals may actually suffer from smoothing, due to 1) discrepancies between the return residual distribution parameters in the retail and residential sectors compared to those found in earlier studies, and 2) the fact that appraisal- and transaction-based return residual distributions differ significantly. For office properties, the results are different, because the distribution of appraisal-based returns is similar to its transaction-based equivalent.

However, whether the leptokurtosis in property return distributions is due to appraisal smoothing, especially as the alphas for transaction returns are significantly higher, is beyond the scope of this study. At present, there is no way to definitively determine whether differences in parameter estimates for transaction return residuals are the effect of properties being sold in years with large changes in market value, or simply of smoothing in property appraisals.

\section{Appendix}

Figure A. 1

Total Return Residual Distribution (2000-2009)

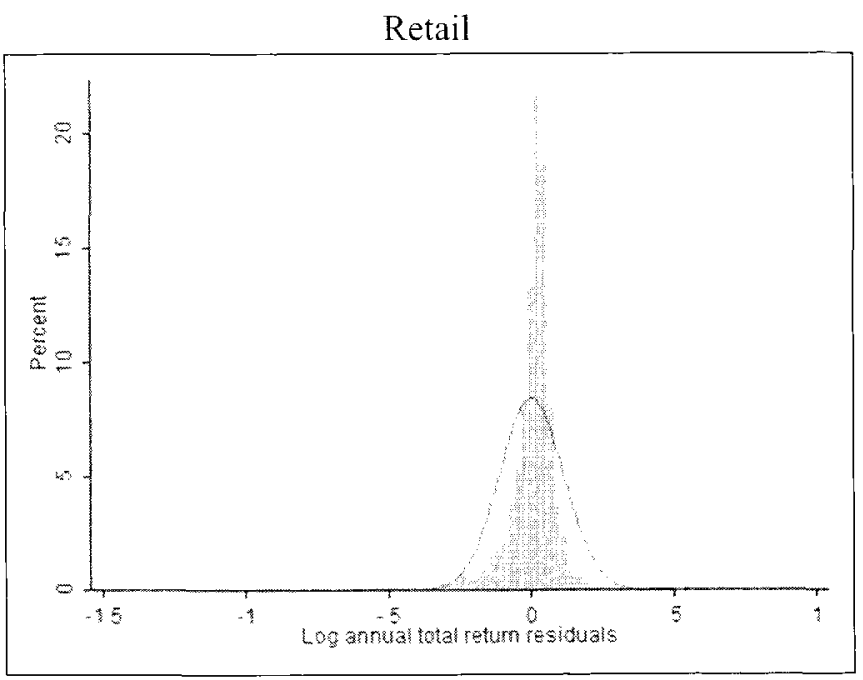

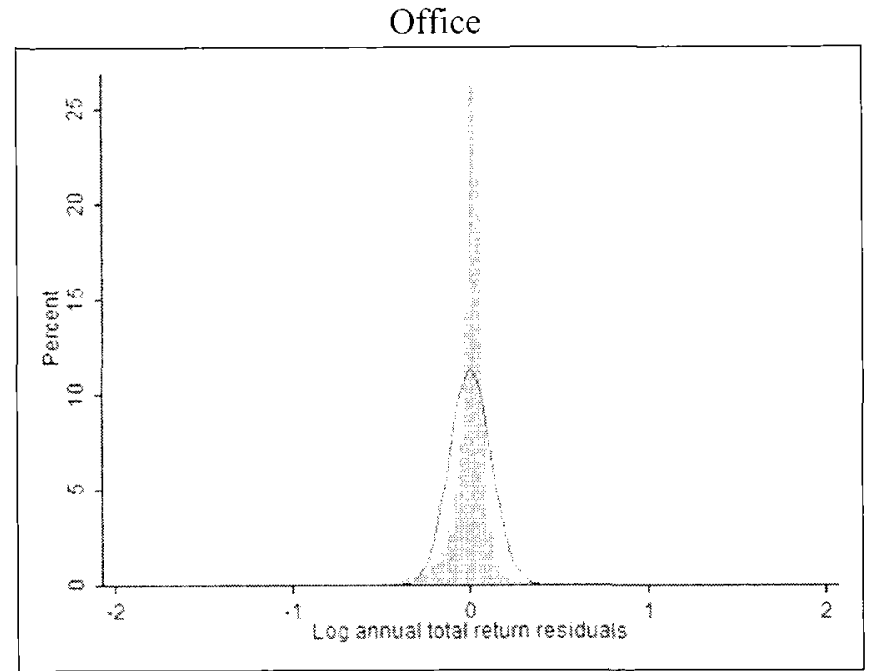

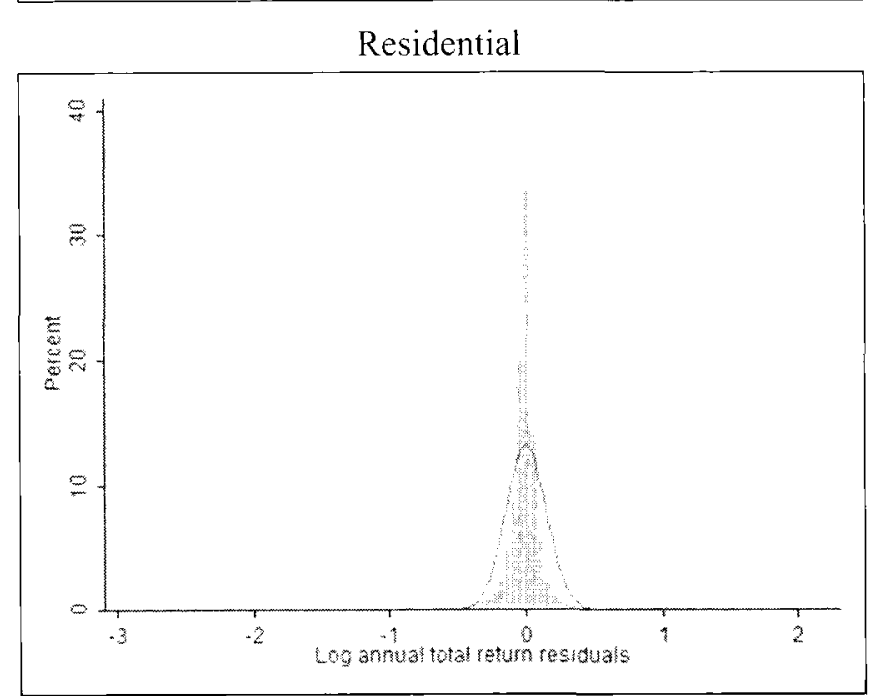

Notes: The data come from IPD. Annual log return residuals were assigned to 100 bins of equal size. Scaling of the $x$-axis shows the values of the $\log$ annual return residuals (i.e., 1 equals 100\%), while the $y$-axis displays the percentage of returns assigned to the corresponding bin. The solid line represents the normal distribution.

\section{Endnotes}

1. For an extended literature overview, see, for example, Norman, Sirmans, and Benjamin (1995) and Benjamin, Sirmans, and Zietz (2001).

2. For a detailed description of return distribution parameters and asset-specific risk, see the Data and Methodology section.

3. International valuation models usually account for a shorter economic useful life by applying a higher cap rate, which provides comparable valuation results as the German valuation model.

4. Berlin, Dusseldorf, Frankfurt, Hamburg, and Munich are the most significant local investment markets in Germany. These cities have the largest number of properties in the dataset. 
5. If appraisals are assumed to be smoothed, then changes in appraised market values should be smaller than changes in true (but unknown) market values until the discrepancy between the two becomes evident and triggers a large change in value (compared to the other appraisal-based changes in value). Therefore, it seems reasonable that a series of smoothed returns would result in a more leptokurtic distribution exhibiting lower alphas and higher gammas than transaction-based returns.

6. Transaction-based returns are computed in years when a property is sold. Thus, the determining parameter for capital growth in these years is not a change from one appraised value to another, but the change from the last appraised value to the sales price. Note sales are excluded where the seller is a German open-ended fund because the German Investment Act (InvG) prohibits open-ended funds from selling properties below market value. Thus, any sales executed by open-ended funds could bias the results, because the nonnegative capital growth would skew the distribution.

7. It has become commonly accepted in the literature that property appraisals are affected by smoothing. The existence of smoothing can require a procedure for unsmoothing in order to improve volatility estimates, at least on an aggregated index level. See Geltner, MacGregor, and Schwann (2003) for a literature review. Empirical evidence on smoothed individual property appraisals can be found, for example, in Clayton, Geltner, and Hamilton (2001). These authors also conclude that appraisers tend to anchor their valuations to previous appraised values, which could explain the peaked and narrow return distributions.

8. If any of the property appraisals, for any reason, do not accurately reflect market values, neither the presented values for annual transaction data nor the valuation data itself would provide accurate information. If appraisals are inaccurate, then income return numbers would be biased as well, because the (estimated) property value of the previous year is part of the formula for income return. Transaction-based returns would also be inaccurate. If investors believe that property appraisals reflect true market value, distribution parameters for income return, capital growth, and total return may be used for further risk analyses.

9. An analysis of subsamples according to property quality is not possible with the given dataset.

\section{References}

Benjamin, J.D., G.S. Sirmans, and E.N. Zietz. Return and Risk on Real Estate and Other Investments-More Evidence. Journal of Real Estate Portfolio Management, 2001, 7:3, 183-214.
Byrne, P. and S. Lee. Real Estate Portfolio Analysis under Conditions of Non-Normality: The Case of NCREIF. Journal of Real Estate Portfolio Management, 1997, 3:1, 37-46.

Clayton, J., D. Geltner, and S.W. Hamilton. Smoothing in Commercial Property Valuations-Evidence from Individual Appraisals. Real Estate Economics, 2001, 29:2, 337-60.

Coleman, M.S. and A. Mansour. Real Estate in the Real World: Dealing with Non-Normality and Risk in an Asset Allocation Model. Journal of Real Estate Portfolio Management, 2005, 11: $1,37-53$.

Geltner, D., B.D. MacGregor, and G.M. Schwann. Appraisal Smoothing and Price Discovery in Real Estate Markets. Urban Studies, 2003, 40: 5-6, 1047-64.

Graff, R.A., A. Harrington, and M.S. Young. The Shape of Australian Real Estate Return Distributions and Comparisons to the United States. Journal of Real Estate Research, 1997, 14: 3, 291-308.

Investment Act (InvG) (2008) 2003-12-15 (BGBl. I p. 2676). As amended on 2008-08-13 (BGBl. I p. 1690).

Maurer, R., F. Reiner, and S. Sebastian. Characteristics of German Real Estate Return Distributions: Evidence from Germany and Comparison to the U.S. and U.K. Journal of Real Estate Portfolio Management, 2004, 16:1, 59-76.

McCulloch, J.H. Simple Consistent Estimators of Stable Distribution Parameters. Communications in Statistics-Simulation and Computation, 1986, 15:4, 1109-36.

Myer, F.C.N., and J.R. Webb. Return Properties of Equity REITs, Common Stocks, and Commercial Real Estate: A Comparison. Journal of Real Estate Research, 1993, 8:1, 87-106.

Norman, E.J., G.F. Sirmans, and J.D. Benjamin. The Historical Environment of Real Estate Returns. Journal of Real Estate Portfolio Management, 1995, 1:1, 1-24.

Schulte, K.W., N. Rottke, and C. Pitschke. Transparency in the German Real Estate Market. Journal of Property Investment and Finance, 2005, 23:1, 90-108.

Young, M.S. Revisiting Non-normal Real Estate Return Distributions by Property Type in the U.S. Journal of Real Estate Finance and Economics, 2008, 36:2, 233-48.

Young, M.S., and R. Graff. Real Estate is Not Normal-A Fresh Look at Real Estate Return Distributions. Journal of Real Estate Finance and Economics, 1995, 10:3, 225-59.

Young, M.S., S.L. Lee, and S.P. Devaney. Non-Normal Real Estate Return Distributions by Property Type in the UK. Journal of Property Research, 2006, 23:2, 109-133. 